\title{
Making the sustainable energy colloquy quantitative and accessible to all
}

\section{In memoriam David J.C. McKay FRS}

The late David McKay, Regius professor at Cambridge University Department of Engineering, helped to create a meaningful dialogue about what sustainability means, what it would take, and what policies would be needed. He always did so in a factual and humorous way. His web page compares his book "Information Theory, Inference and Learning Algorithms" to Harry Potter; of course, his book comes out on top. One of his most defining steps in the energy and sustainability area was the self-publishing of "Sustainable Energy without the Hot Air" in 2008. In this book he discusses renewable/alternative/ sustainable energy in quantitative and practical terms, using straightforward arithmetic to focus arguments. This was written at a level to be accessible to a very broad community and helped define a generation of students' perspective in this area. He took arguments that had previously been almost by-decree and moved them to a level where a clear methodology could be employed, thereby enabling statements with regard to impact on energy and climate to be based on clear facts and often by numerically backed assumptions, with which calculations can be done to make a point. If one disagrees with the assumptions, one can change them and redo the calculation to see how this would change the outcome, allowing the readers to logically develop their own opinions.

While those that work with science and engineering and employ the scientific method think of this as a matter of course, the heavily politically and emotionally loaded areas of energy and sustainability often move more to declarative statements. This makes his approach so much more powerful, providing a foundational understanding accessible to whoever is willing to put in an effort equivalent to what was required to finish elementary school. This and his subsequent work were truly a major step towards creating a sensible dialogue about these critical topics.

The book helped to define the whole field by factually and logically presenting information and showing how to perform calculations. The fact that the book was available free to everyone (as was his other book) was a masterstroke making it an indispensible resource.

It showed to those afraid of science and engineering that there is nothing to be afraid of as long as one dares to read what he called the "non-technical" chapters (no arithmetic formulae) and accept use of numbers. In this way he put to practice what Lord Kelvin (William Thomson) stated in his 1883 lecture on "Electrical Units of Measurement," published in Popular Lectures Vol. I, p. 73 :

"I often say that when you can measure what you are speaking about, and express it in numbers, you know something about it; but when you cannot measure it, when you cannot express it in numbers, your knowledge is of a meagre and unsatisfactory kind; it may be the beginning of knowledge, but you have scarcely, in your thoughts, advanced to the stage of science, whatever the matter may be."

The many translations and foreign versions of (parts or all of) his book attest to its international importance. And this book was just a small part of the work of this amazing person, as his day job was research in and teaching of machine learning and information theory, apart from a stint as chief scientist of the United Kingdom Department of Energy and Climate Change.

MRS Energy and Sustainability: a Review Journal as a journal strives to publish papers that follow the spirit of "Sustainable Energy without the Hot Air" and provide information and views that are quantified as much as possible and in way that can be checked.

Personally, we will continue to use the book and its teaching to help educate new generations of students to be aware of the serious energy, climate, and sustainability challenges we all face and to hope that they can follow in the footsteps of David McKay. His insightful contributions and balanced perspective will be truly missed by all, who have a genuine interest in objective dialogues on the subject of sustainable energy and on how the scientific method can contribute to public discussions in general.

https://www.theguardian.com/environment/2016/apr/ 18/sir-david-mackay-obituary

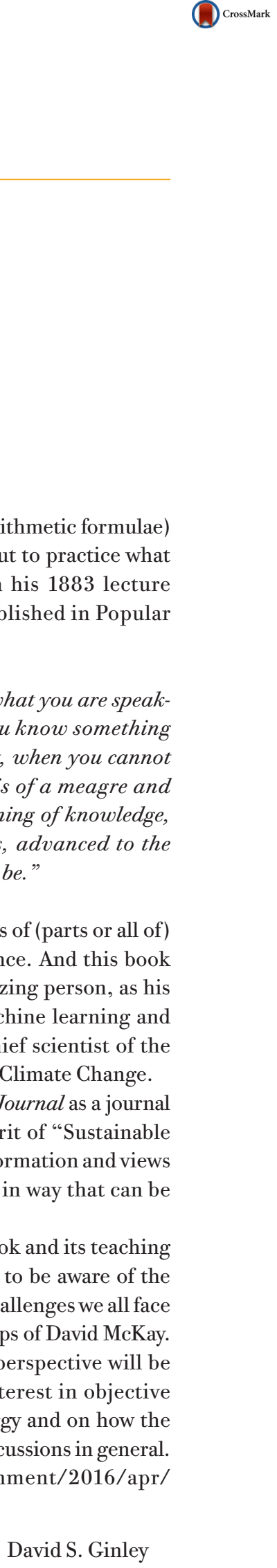

David Cahen

Elizabeth A. Kócs

Editors-in-Chief

July 2016 